\title{
Latino Studies logo designer
}

Born in a suburb of Chicago, David Muñoz-Armstrong graduated from the University of Iowa with a degree in Anthropology. He obtained his design education at Columbia College. He has worked on projects for a multitude of clients - both corporate and academic. His work includes print, illustration, and Web design. He is employed as a designer in Chicago.

When designing the logo for Latino Studies, I wanted it to symbolize the journal's aim. I chose to design a non-descript figure using a brush effect to give the feeling of pride, momentum, progression, and energy. To have a sun in the background seemed a natural choice; not only did it illustrate our roots but it added a voice to solidify the symbol. In the end, I hope I succeeded in illustrating one of the most racially and culturally diverse group of people.

Latino Studies (2003) 1, 204. doi:10.1057/palgrave.1st.8600001 